\title{
Timing of Shunt Insertion in Children with Neural Tube Defects and Hydrocephalus: A Clinical Study
}

\author{
Ahmed ANSARI \\ Uttar Pradesh University of Medical Sciences, Department of Neurosurgery, Saifai, Etawah, UP, India
}

Corresponding author: Ahmed ANSARI ahmed.ansari2@gmail.com

\section{Dear Editor}

W e read with great interest the article by Ozgural et al. regarding timing of shunting in children with neural tube defects and hydrocephalus (1). We agree that the timing of shunt insertion in patients with neural tube defects is still a controversy. Our point of view is favoured towards shunt insertion prior to definitive surgery in the same sitting, owing to the fact that prior shunt insertion relaxes the larger sacs. However, in patients with fragile skin, we believe that deferring the definitive surgery after shunting gives time for the child to grow with a better skin cover later on.

The authors point towards the fear of sac rupture during prior shunt surgery. In our practice, we always elevate the child's back over a head ring stuffed with cotton around it during intubation and shunting; and we have never encountered any ruptured sac with this technique.
We have also seen cerebrospinal fluid (CSF) leakage in several patients without hydrocephalus in post operative period, which is really difficult to deal with. In such patients, usage of tension sutures at the point of leakage in the wound (wide 3-0 Ethilon sutures with cut infant feeding tube between them) stops CSF leakage. Also, in cases of mild hydrocephalus, we release every bit of arachnoid at the cord protrusion in NTDs making way for clear CSF flow before closing.

We really look forward for a multicentric, multi-surgeon study regarding timing of shunt insertion in neural tube defect patients.

\section{REFERENCES}

1. Ozgural O, Kahilogullari G, Dogan I, Eroglu U, Yakar F, Kilinc MC, Sayaci EY, Unlu MA: Timing of shunt insertion in children with neural tube defects and hydrocephalus: A clinical study. Turk Neurosurg 30(2):194-198, 2020 